\title{
The Prominent Barriers to Speaking in English: A Study Conducted Among Youngsters
}

\author{
Aby John ${ }^{1}$ \\ ${ }^{1}$ PhD Scholar, PG \& Research Department of English, Presidency College (Autonomous), Chennai, Affiliated to \\ the University of Madras, India \\ Correspondence: Aby John, PG \& Research Department of English, Presidency College (Autonomous), Chennai, \\ Affiliated to the University of Madras, India. E-mail: abyjohndr@gmail.com
}

Received: June 2, $2020 \quad$ Accepted: July 4, $2020 \quad$ Online Published: July 17, 2020

doi:10.5539/ijel.v10n5p190 URL: https://doi.org/10.5539/ijel.v10n5p190

\begin{abstract}
This discourse analyses the prominent barriers to speaking in English while conducting online English Language classes during the pandemic, COVID-19. The study is conducted among business communication students in university colleges in India and takes five paradigms into consideration. They are: the motivational factor, the personality of the learner, attitude of the learner, the pedagogical management of English classes in online mode and the level of exposure to the English language. Data were collected by analyzing the survey questionnaire distributed among 150 business communication students. Data were analyzed with the help of SPSS in a descriptive mode. The result of the analysis shows that while dealing with online classes, teachers face several difficulties to manage the language subjects, especially the pedagogical management of the English subject. Another significant factor is the level of exposure to the English language. In this online system, ordinary students do not have an opportunity to communicate and practice English. They show some kind of hesitation to use English during the entire class time and give less attention to the words of the teacher. Most of them are distracted due to several factors. It contributes moderately to the predicaments of the learners. This study also helps to understand the crucial factors that act as language barriers in cross cultural business communication as the application level of language is more or less same all over the world.
\end{abstract}

Keywords: business communication, English, teaching pedagogy, Covid-19, English language teaching

\section{Introduction}

In the realm of business, English acts as a significant tool for communication across varied cultures, especially in a multilingual context. Good communication skill is inevitable for good business deals. A common link language like English is needed for the efficient and effective communication purposes. In most of the cases, people express themselves orally and therefore, speaking is considered as the principal and productive language skill. Conversing in any non-native language is really demanding as the speakers are supposed to have proper knowledge and understanding of important elements of the non-native language. The speaker should be thorough with the major elements of the language like comprehension, diction, pronunciation, elements related to grammar and fluency in order to communicate properly. Youngsters who are fluent in using the English language usually have better opportunities to secure attractive job offers across the globe. The employers focus not only on the academic and technical expertise while selecting the graduate employees. Along with the technical know-how, employers also focus on the much-needed soft skills of the employees before hiring them. Another important thing is that most of the interviews are being dealt with in English. Therefore, proficiency in communicating in English is inevitable for the candidates to impress the interview board.

Usage of the English language with high level of confidence will help the candidates a lot in securing the job easily. In several cases, it is clear that the employers choose candidates from deemed universities or private universities due to the candidates' high potential to use the English language in an efficient and effective manner. As a whole, in India, the relevance of English is really incredible. Well educated youngsters use English occasionally. Those candidates who possess satisfactory communication skills in English meet the demands of globalization: this is the point of view of most of the employers. Such candidates will be given preference in an interview. Therefore, it is crucial to adopt suitable measures to increase and optimize the mastery level and acquisition rate of the speaking skills in English among the youngsters. It will ultimately bring a hike in the employability rate among the 
youngsters.

\section{Literature Review}

In this era of information technology and globalization, English has a predominant role in the communicative sphere of the world. It is taught almost everywhere in the world. It also has a prestigious reputation in the world. In the realm of education, English has a special identity. A link language is a language used by a person who belongs to any national, social or international strata to express himself in a better manner. English has attained such a status in the modern scenario. It has become such a language that is used to express one's feelings and thoughts. It is also used to express the feelings of a social group all over the world. It has thus become a language that is indispensable. It helps to create a universal brotherhood among all the people in the world and functions as a link language. The role of the English language is becoming inevitable in the post-modern era. The purpose of a language is to provide an efficient and effective medium to communicate. In India, several languages are used and English is one of such languages. The Indian society places English on a high pedestal. It is considered as the language of the elite class. General observations make it clear that the language used by the educated people for official communication is English. It is the language of prestige for many. In India, most of the parents try to educate their children in English medium schools. A child's bright future can be ensured by ensuring his/her good knowledge of English. If one is capable of communicating his/her idea in English, he/she is regarded as an intelligent person or a scholar. Many institutions use the English language as their medium of instruction. They operate in English and subjects are taught only in English. The readership of English is increasing day by day and simultaneously its significance too. Many people prefer English to other languages. It has a worldwide acceptance as an international language.

Several factors lead to deficiency in the speaking skills of Indian youngsters even though they are exposed to this language from primary school studies. In order to identify the important aspects that contribute to the barriers, this discourse observed five areas namely motivational factor, the quality of the exposure of the learners to the English language, the attitude of the learners, the pedagogical management of the English language course by the teachers while conducting online classes and the learners' personality.

\section{Factors that Play a Crucial Role in the English Speaking Skills}

Several factors lead to deficiency in the speaking skills of Indian youngsters even though they are exposed to this language from primary school studies. In order to identify the important aspects that contribute to the barriers, this discourse observed five areas namely motivational factor, the quality of the exposure of the learners to the English language, the attitude of the learners, the pedagogical management of the English language course by the teachers while conducting online classes and the learners' personality.

\subsection{Motivational Factor}

Different schools of thought had defined this concept in a precise and clear manner. Oxford \& Shearin describe motivation as a crucial factor in the retention and acquisition processes of a novel language. At all phases of education, success of learning is affected by both extrinsic and intrinsic factors ( $\mathrm{Ng} \& \mathrm{Ng}, 2015)$. Success is based on the intensity of desire and the effort a person puts to attain that goal. This psychological aspect or the instinct which creates that particular action is known as motivation. It is something that incites, stimulates or arouses an action. It can also be comprehended as an amalgamation of strong determination and attempt to accomplish the end of learning a language. Enthusiasm towards acquiring a novel language is added along with this. Motivation is accompanied by several factors.

A motivated person takes the effort towards accomplishing a particular task, but the expended effort may not suggest that the person is strongly and totally motivated (Gardner, 1985). It gives learners a direction and aim. Ultimately, it is a prominent factor in the process of learning language. Lack of motivation can create difficulty in language acquisition. Effective learning can be impeded due to lack of motivation. Basically, there are three prominent factors to motivation as per the studies of Alizadeh. They are: the pleasure derived from the learning process, the attitude a learner has towards the foreign language and extraneous pressure factors (Alizadeh, 2016). The survey conducted proves that the online classes fail to motivate the students to use English for verbal communication. On the other hand, during online sessions, the students are really happy to use English for written communication.

\subsection{The Quality of Learners' Exposure to English}

Multiple factors affect the process of learning a second language. Opportunity to make use the target language is one among them. Briere states that acquisition of the foreign language is highly influenced by the period of time in exposure to a target language in the environment of linguistics (Briere, 1987). Language exposure can be 
understood as the proficiency level and the rate of language acquisition level resulting from the process of learning. Learning a new language can be conducted in its best form in formal and informal manner. Only a formal mode of exposure may not give the desired effect compared to that in formal and informal environment (Sheela, 2016; Ravikumar, 2016). Some activities should be conducted outside the classroom for increasing the language proficiency of the students. Research shows that an exposure given to the students outside the classroom is highly beneficial for acquiring second language. It has a good and positive impact compared to in-class instructions. The vocabulary acquisition was found relatively high in outside classroom practice. The crucial aspects that help in improving the proficiency of the students are interactions between students and teachers and the exposure to English environment in the campus.

But, to the contrary, at the time of this pandemic, no such activities are possible. Online means of teaching cannot provide such an atmosphere to every student as the reach of technology is limited. Moreover, most of the students are not capable of affording huge cost for their studies. The analysis was based on the lexical properties and the quantity of words uttered by both the students and teachers during the online sessions. The findings suggest that the language of the students develops significantly when they interact in English with teachers in a classroom ambience rather than in an online, technology-based system.

\subsection{Attitude}

The success of learning a new language is basically linked to the attitude of the person. Researchers unanimously agreed that motivation and language attitudes are very crucial in the acquisition of the second language (L2) which donates significantly in the readiness of the learners to interact and the willingness to communicate in the second language (Jackson, 2016). A comprehensive study is conducted by Abdullah and Wong in the amalgamated realm of socio-politics and language. The study aimed at finding the relationship between the socio-political nature in India and the attitude of people towards learning English. The researchers also examined the correlation between the attitude of youngsters towards learning the English language and the probable threats it poses on national identity (Abdullah \& Wong, 2017). The study revealed the fact that the respondents who believed in the power of English in political and social realm found its teaching and learning worthy. On the other hand, the respondents who believed that English has an authoritarian power showed an apprehension towards its learning. They believed that English will erase their national and ethnic identity.

In an American college, the relationship between mastery over English speaking skills and attitude of youngsters is analyzed based on a study among 75 Japanese students (Motobayashi \& Takahashi, 2019). The result of the study was astonishing. It was found that a highly positive approach and attitude towards speaking English is developed in the youngsters when they favored speaking English in an ambience away from that of their first language using locality. Smith, Schroth and Kyles studied the personal preferences of the students in learning the language skills (Schroth, 2015; Smith, 2015; Kyles, 2015). The hypothesis was that if the students prefer a particular section of the language more, there is a possibility that they would achieve mastery of the skill or area in a better manner. Out of eleven respondents, six expressed preference for speaking. As per the hypothesis, it should positively affect their capacity of speaking. But to the contrary, the area of language that was positively influenced was writing. Surprisingly, the students' affinity or preference for speaking incredibly influenced the usage of verb in a proper manner. However, it did not have influence on their usage of verbs in spoken language in a significant amount.

\subsection{Teachers' Pedagogical Management of Online English Class}

What are the major impediments to learn English in the process of acquisition of speaking skills among Business Communication students? This factor is mainly based on the pedagogical approach and management of the online classes by the teachers. The learners' performance can be increased significantly if a teacher gives priority to his or her pedagogy in the language class. The methodology a teacher adopts in the process of teaching is a crucial aspect in the process of acquisition of language. Selamat and Hassan in their study identified that the syllabus of the English subject only emphasized writing and reading skill giving least importance to speaking and listening skill (Selamat \& Hassan, 2017). Another crucial factor that affects the speaking skill of the student is that teachers are giving prime importance to grammatical rules neglecting the importance of speaking and listening skills. It is found that better learners are those students who are provided with continuous and spontaneous inspiration, a well-explicated idea of the techniques used in speaking and voluntary support from the faculty members outside and inside the walls of the classroom (Ahmed, 2018). Another study shows that language learners' oral skills and motivation may be threatened by the unsuitable teaching styles in the classroom. In order to explore the target or foreign language, teachers dealing with language subjects are highly recommended to provide space and opportunities for their students to speak in English. This helps students to overcome the language barriers that may impede their acquisition of language. To a great extent, online classes hamper such opportunities which students 
could avail in the offline mode.

\subsection{The Personality of the Learner}

Another crucial aspect which affects a student's language development and willingness to communicate in foreign language is the personality trait. Various scholars have conducted studies on the relationship between language learning and the personality of the learner. Second language acquisition and personality are correlated strongly. The failure or the success of the language learning process is linked to the learner's personality. The introverted ones will be slow in responding in the target second language compared to an extrovert person (Ehrman, Krashen, \& Skehan, 1989). Introverts acquire or respond in second language in a slower manner compared to an extrovert. Therefore, it is crucial for an extrovert to get acquainted with some other means to get acclimatized to the communicative elements. There are five important aspects related to the personality of the learner in the process of language learning and they are conscientiousness, agreeableness, neuroticism, openness, and extroversion. A learner's personality trait is directly linked to his or her willingness to communicate (WTC) in a foreign or second language. This readiness can further be influenced by the situations of the learner. In the context of WTC, conscientiousness and agreeableness, both had a negative and direct relationship to WTC in a non-native language. On the other hand, openness to experience does not have an impact on learners' WTC. Moreover, neuroticism affects WTC in a positive and direct manner. Thus, as a conclusion, it is clear that WTC and personality traits have direct relation with WTC in foreign language.

A prominent researcher, Hassan, conducted a study to investigate the positive relationship between the acquisition of language and personality. The study was based on 48 Arabic native speakers who lived and studied in KSA. The participants had a crucial mother tongue influence while speaking in English. Those students who tried to deliberately link themselves with the culture and tradition of the acquired language (learned language) were found to have better English accent than others. The output is that personality is an important factor and predictor of native accent acquisition in the process of learning and acquiring language (Hassan, 2018).

\section{Methodology Used}

\subsection{Samples and Population}

The study was conducted among students who have business communication as one of their subjects. The number of students participated in the survey was 150 . One hundred and twenty respondents were male were as the rest were females. The average age of the group was 22 .

\subsection{Research Instrument}

Data were collected by distributing questionnaires which had two parts. The first part of the questionnaire dealt with the demographics of the respondents such as age, gender, programme of study and semester. The second part of the questionnaire consisted of questions with close-ended nature with thirty-seven items. Likert scale (five point) was used to measure each question which inspired the participants to reveal their point of view regarding motivation, exposure to English, attitude, personality of the respondent and the language teachers' pedagogical management while conducting classes in online mode. The measures used for assessing the degree of problems are lowest (1.00-1.49), low (1.50-2.49), moderate (2.50-3.49), high (3.50-4.49) and highest (4.50-5.00).

\subsection{Data Analysis}

Statistical Package of Social Sciences (SPSS) was used for the statistical analysis of the data. Windows applications supported it. In order to rank the questionnaire from the highest to the least, descriptive statistics were utilized. A t-test was also performed to identify the variations of the mean scores between the two variables.

\section{Results}

The discourse aimed at answering the following questions:

Question 1: What are the prominent aspects that influence and ultimately affect the English language speaking skills of Business Communication learners?

The primary intention of the current study is to comprehend the crucial aspects that influence English speaking skills among the students of business communication. The final output of the study revealed that the problems of the students in acquiring the speaking skills in English were moderate. After analyzing each factor, it was understood that the level of exposure to the English language, the pedagogical management and learners' own personality were considered moderate by the respondents. Moreover, it was also found that the attitude and motivational factors of the students as low in the acquisition of speaking skills in English. 
Table 1. Factors that play a crucial role in the English-speaking skills of Business Communication Students

\begin{tabular}{llll}
\hline Factors affecting English Speaking Skills & \multicolumn{3}{l}{ Total $(\mathrm{N}=150)$} \\
\cline { 2 - 4 } & Mean & SD & Frequency of Factors \\
\hline 1. Attitude & 2.31 & 0.74 & Low \\
2. Motivational Factor & 2.14 & 0.65 & Low \\
3. Personality & 2.71 & 0.86 & Moderate \\
4. Exposure to English & 2.89 & 0.96 & Moderate \\
5. English Teaching and Learning Management & 3.11 & 0.99 & Moderate \\
Total & 2.632 & 0.84 & Moderate \\
\hline
\end{tabular}

Table 1 indicates the factors that play a significant role in the acquisition of English-speaking skills and the average frequency of the factors as expressed by 150 business communication students. The output shows that the factors that influenced the speaking skills in the English language were moderate (Mean = 2. 63). Out of five factors, these were rated as moderate. That is, English teaching and learning management (Mean $=3.11$ ) followed by exposure to the English language (Mean $=2.89$ ) and at last the personality of the students (Mean = 2.71). The factors that seemed to be low by the respondents were the attitude of the students (Mean $=2.31$ ) and the motivational factors with a mean of 2.14 (Mean $=2.14$ ).

Question 2: Is there any relevant difference in the factors affecting the speaking skill of English between female and male business communication students?

This section presents a comparison between the above mentioned five causes which affects the oral proficiency skills in the English language between female students and male students studying business communication. The significance level of the difference was pointed out by running a t-test. The value of significance was set $<.05$.

Table 2. Comparison between five factors that affect the English language speaking skills between female and male business communication students

\begin{tabular}{llllll}
\hline \multirow{2}{*}{ Factors affecting English speaking skills } & \multicolumn{3}{l}{ Gender } \\
\cline { 3 - 5 } & & Male & \multicolumn{3}{l}{ Female } \\
\cline { 3 - 5 } & Mean & SD & Mean & SD \\
\hline 1. & Attitude & 2.35 & 0.77 & 2.20 & 0.61 \\
2. & Motivational Factor & 2.20 & 0.65 & 2.13 & 0.63 \\
3. & Personality & 2.73 & 0.90 & 2.72 & 0.85 \\
4. & Exposure to English & 2.94 & 0.99 & 2.72 & 0.85 \\
$5 . \quad$ Management & 3.16 & 1.09 & 3.12 & 0.74 \\
\multicolumn{2}{l}{ Total } & 2.67 & 0.88 & 2.578 & 0.73 \\
\hline
\end{tabular}

Note. Statistical Significance at .05 level.

Table 2 points that the mean scores of the factors that affect speaking skills in English shown by the male students in the study (2. 67) were higher than that indicated by the female students (2. 578) but not at a significant level $\mathrm{P}<.05$ as the reading was $(0.88)$. This makes clear that here is no statistical variation between the factors that contribute to English speaking skills between female and male students in the study.

\section{Discussion of Findings}

Discussion and Findings of the First Question: As is clear from the result of the study, all the factors have some sort of significance in developing the speaking skills of the students. Out of 5 factors, three were presented as moderate. They are the effective pedagogical management of English lessons by the teachers, the personality of the students and the quality of exposure to English. The factors that were rated low by the respondents were motivation and attitude.

Firstly, the factor with regard to the proper and effective management of the learning and teaching of the English language consists of the pedagogical techniques used by the teachers in conducting online classes. The students are highly interested in activities related to fun field trip but unfortunately, it is not possible during this crucial time of the pandemic. Another aspect in the pedagogical management of the lessons deals with short courses and summer camping in the target language $($ Mean $=3.24)$. This implies that learners really enjoy the opportunities they get to explore and the exposure to real life situations where they can utilize and make use of the target language. Exposure to speak in English is the next concern of the learners. They expressed the idea of communicating in the target language at home with their siblings as well as parents (Mean =3.23). It shows that this is the result of their desire to increase familiarity and self-confidence while speaking in English. 
Opportunity to practice English among their peers was another item which was of crucial significance (Mean $=2$. 96). It implies that the students realized the necessity for having a very good contact in the target language as a means of improving English speaking skills.

Another crucial aspect that determines the success in learning and communicating using the target language is the personality of the students. The respondents were worried about making mistakes while speaking in the acquired language (Mean $=3.15$ ). They were also tensed of being made a laughing stock upon creating mistakes with regard to grammar. The findings of the present study go hand in hand with the research conducted by Tati et al. (Tati, Paul, \& Golingi, 2016) and Salleh (Idrus \& Salleh, 2017). They state that self-efficacy is a prominent aspect in determining the success of learning language and lack of self-confidence of the learners may hinder their progress of learning.

The fourth factor which plays a key role in English speaking skill of students is attitude. The respondents regarded this factor as low. Almost every student participated in the study were positive towards it and they were well aware of the significance of fluent speaking skills in English (Mean $=1.77)$. This result also coincides with that of Ahmmed (2018).

The last factor, motivation, was considered by the respondents as of having the lowest impact. They had a great concern over the slow improvement of their proficiency of speaking (Mean $=2.87)$. It well-depicted the learners' lack of self-confidence while communicating with foreigners who speak English or to a native speaker (Mean = 2.85). The learners were well-aware of the fact that English is very important for their career prospects. It is crucial to learn to communicate in English (Mean $=1.63$ ).

Discussion and Findings of the Second Question: The outcome of the research proved that there was no prominent difference in the overall factors affecting the English language speaking skills between female as well as male business communication students at a significance level of .05. It also reaffirms the contemporary studies and states that the difference between female and male students in foreign language learning was of no significance.

\section{Implications of the Study and Conclusion}

The study conducted unveils the fact that one of the biggest concerns of the student community is speaking in English outside the classroom. Therefore, it is apt and really advisable to find avenues and options to have interactive sessions in target language outside the classroom. At the present situation of Covid-19, students have minimal options to have direct face to face interactions with their friends and classmates. To a great extent, they can make use of the technological advancements and online means to overcome this crisis. Short courses on English language can also help students to overcome the barriers as such courses provide an awareness regarding their loopholes. Activities based on the usage of English and games dealing with the target language ease students and make them tension free while making mistakes. It can be practiced online as well. Once the situation becomes normal, students can practice communicating in the target language both in an informal and formal manner. All these activities and practices act as a means for the students to have a wider exposure to different language learning situations. Ultimately, it will help the students to improve their self-confidence level to a great extent. Teachers can play the role of a leading lamp in supporting the students to achieve the goal.

\section{References}

Abdullah, M. H., \& Wong, B. E. (2017). Listening to the ethnic voice in ESL learning. The English Teacher, 35, $15-26$.

Ahmed, M. K. (2018). Pedagogy in Speaking: Challenges Addressed by Teacher-Student in the ESL Context. International Journal of Applied Linguistics \& English Literature, 7(3), 97-107. https://doi.org/10.7575/aiac.ijalel.v.7n.3p.97

Ahmmed, R. (2018). The Difficulties of Maritime Communication and the roles of English Teachers. BMJ, 1(1), $26-34$.

Alizadeh, M. (2016). The impact of motivation on English language learning. International Journal of Research in English Education, 1(1), 11-15.

Briere, J. E. (1987). Variables affecting native Mexican children learning Spanish as a second language. Language Learning, 28(1). https://doi.org/10.1111/j.1467-1770.1978.tb00312.x

Ehrman, M. E. (1996). Understanding Second Language Learning Difficulties. Thousand Oaks, California: SAGE Publication.

Gardner, R. C. (1985). Social psychology and second language learning: The role of attitude and motivation. 
London: Edward Arnold.

Hassan, F., \& Selamat, N. F. (2017). Why aren't students proficient in ESL: The Teachers' Perspective. The English Teacher, 31, 107-123.

Hassan, W. (2018). The Effect of Personality and Accent Acquisition: Case study of Effat University Students. $A$ Journal of English Studies, 33-48. https://doi.org/10.15290/cr.2018.22.3.02

Idrus, H., \& Salleh, R. (2017). Perceived self-efficacy of Malaysian ESL engineering and technology students on their speaking ability and its pedagogical implications. The English Teacher, 37, 61-75.

Jackson, J. (2016). The language use, attitudes and motivation of Chinese students prior to a semester-long sojourn in an English speaking environment. Study Abroad Research in Second Language Acquisition and International Education, 1(1), 4-33. https://doi.org/10.1075/sar.1.1.01jac

Krashen, S. (1985). The Input Hypothesis: Issues and Implication. London: Longman.

Motobayashi, S., \& Takahashi, T. (2019). Changes in Japanese ESL speakers' identities and in their attitudes towards speaking English. The Journal of Language Teaching and Learning, 9(1), 31-52.

Ng, C. F., \& Ng, P. K. (2015). A Review of Intrinsic and Extrinsic Motivations of ESL Learners (pp. 24-31). A Review of Intrinsic and Extrinsic Motivaion of ESL Learners. Proceedings of the International Conference on Culture, Languages and Literature, Kuala Lumpur, Malaysia. https://doi.org/10.7763/IJLLL.2015.V1.20

Schroth, T., Smith, B., \& Kyles, E. (2015). Language Learning Background and Attitudes in ESL Contexts: The Case of Verb Acquisition. The Journal of Language Teaching and Learning, 2, 74-85.

Sheela, S. K., \& Ravikumar, K. (2016). The importance of exposure in learning English as a second language-Strategies to be employed to improve student's language exposure in the context of rapid changes in the field of technology. Research Journal of English language and Literature, 4(2), 770-774.

Skehan, P. (1989). Individual Differences in Second Language Learning. London: Edward Arnold.

Suzuki, S., Harada, T., Eguchi, M., Kudo, S., \& Moriya, R. (2017). Investigating the relationship between students' attitudes towards English medium instruction and L2 speaking. Essays on English language and literature, 46, 25-41.

Tati, J. S., Paul, C., \& Golingi, L. B. (2016). English Language Speaking Anxiety among Community College Learners: How Can It Be Overcome? PEOPLE: International Journal of Social Sciences, 2(3), 38-53. https://doi.org/10.20319/pijss.2016.23.3853

\section{Appendix A}

\section{QUESTIONNAIRE}

PART - I

\section{Background Information}

1) What is your gender?

2) What is your age?

3) Mention your programme of study and current semester?

\section{PART - II}

Questions related to the motivational factor, the personality of the learner, attitude of the learner, the pedagogical management of English classes and the level of exposure to the English language.

1) I feel confident while speaking with native speakers of English
a) Strongly Disagree
b) Disagree
c) Neither Agree nor Disagree
d) Agree
e) Strongly Agree 
2) I feel motivated while communicating with native speakers of English
a) Strongly Disagree
b) Disagree
c) Neither Agree nor Disagree
d) Agree
e) Strongly Agree

3) School level education affects level of confidence to speak in English
a) Strongly Disagree
b) Disagree
c) Neither Agree nor Disagree
d) Agree
e) Strongly Agree

4) I feel confident to speak in English in friends' circle
a) Strongly Disagree
b) Disagree
c) Neither Agree nor Disagree
d) Agree
e) Strongly Agree

5) While speaking with teachers I feel comfortable to use English
a) Strongly Disagree
b) Disagree
c) Neither Agree nor Disagree
d) Agree
e) Strongly Agree

6) I find classroom activities helpful to improve English language proficiency
a) Strongly Disagree
b) Disagree
c) Neither Agree nor Disagree
d) Agree
e) Strongly Agree

7) Watching movies in English helps a lot in improving language proficiency
a) Strongly Disagree
b) Disagree
c) Neither Agree nor Disagree
d) Agree
e) Strongly Agree

8) I daily watch English news to improve English language fluency
a) Strongly Disagree
b) Disagree
c) Neither Agree nor Disagree
d) Agree
e) Strongly Agree 
9) Skits and stage programmes in English helps a lot in increasing my English speaking ability
a) Strongly Disagree
b) Disagree
c) Neither Agree nor Disagree
d) Agree
e) Strongly Agree

10) Fun games and outdoor activities have boosted my speaking skills in English
a) Strongly Disagree
b) Disagree
c) Neither Agree nor Disagree
d) Agree
e) Strongly Agree

11) I feel that online classes help me to improve my communication skill
a) Strongly Disagree
b) Disagree
c) Neither Agree nor Disagree
d) Agree
e) Strongly Agree

12) Various means of exposure to English helps a lot in developing speaking skills in English
a) Strongly Disagree
b) Disagree
c) Neither Agree nor Disagree
d) Agree
e) Strongly Agree

13) I favour an ambience that helps to improve my speaking skills in English
a) Strongly Disagree
b) Disagree
c) Neither Agree nor Disagree
d) Agree
e) Strongly Agree

14) The English language has a strong political and social relevance
a) Strongly Disagree
b) Disagree
c) Neither Agree nor Disagree
d) Agree
e) Strongly Agree

15) Living in an atmosphere away from your native language helps you to use English
a) Strongly Disagree
b) Disagree
c) Neither Agree nor Disagree
d) Agree
e) Strongly Agree 
16) Attitude of friends influence my tendency to speak in English
a) Strongly Disagree
b) Disagree
c) Neither Agree nor Disagree
d) Agree
e) Strongly Agree

17) I want to speak in English as a native speaker
a) Strongly Disagree
b) Disagree
c) Neither Agree nor Disagree
d) Agree
e) Strongly Agree

18) I am not interested in English class
a) Strongly Disagree
b) Disagree
c) Neither Agree nor Disagree
d) Agree
e) Strongly Agree

19) My friends are nervous while speaking in English
a) Strongly Disagree
b) Disagree
c) Neither Agree nor Disagree
d) Agree
e) Strongly Agree

20) I could improve my speaking skills in English if I had many native English-speaking friends
a) Strongly Disagree
b) Disagree
c) Neither Agree nor Disagree
d) Agree
e) Strongly Agree

21) I do not like English
a) Strongly Disagree
b) Disagree
c) Neither Agree nor Disagree
d) Agree
e) Strongly Agree

22) I would like to spend time improving English language skills
a) Strongly Disagree
b) Disagree
c) Neither Agree nor Disagree
d) Agree
e) Strongly Agree 
23) I love to read English newspapers as it helps me to improve my language skill
a) Strongly Disagree
b) Disagree
c) Neither Agree nor Disagree
d) Agree
e) Strongly Agree

24) Being an extroverted individual, I find it easy to acquire speaking skills in English
a) Strongly Disagree
b) Disagree
c) Neither Agree nor Disagree
d) Agree
e) Strongly Agree

25) I use every opportunity which I get to communicate in English
a) Strongly Disagree
b) Disagree
c) Neither Agree nor Disagree
d) Agree
e) Strongly Agree

26) I deliberately try to link myself with the culture of Western countries for improving English speaking skills
a) Strongly Disagree
b) Disagree
c) Neither Agree nor Disagree
d) Agree
e) Strongly Agree

27) I am not at all bothered about speaking in English
a) Strongly Disagree
b) Disagree
c) Neither Agree nor Disagree
d) Agree
e) Strongly Agree

28) My English teacher has a vibrant nature and is talented in teaching English
a) Strongly Disagree
b) Disagree
c) Neither Agree nor Disagree
d) Agree
e) Strongly Agree

29) The teaching methodology of our English teacher helps us to improve in English language
a) Strongly Disagree
b) Disagree
c) Neither Agree nor Disagree
d) Agree
e) Strongly Agree 
30) My English teacher always communicates in English
a) Strongly Disagree
b) Disagree
c) Neither Agree nor Disagree
d) Agree
e) Strongly Agree

31) The way my English teacher organises syllabus helps us to learn and understand the lessons in a better manner
a) Strongly Disagree
b) Disagree
c) Neither Agree nor Disagree
d) Agree
e) Strongly Agree

32) I am worried about speaking in English outside the classroom
a) Strongly Disagree
b) Disagree
c) Neither Agree nor Disagree
d) Agree
e) Strongly Agree

33) I am not interested to speak in English
a) Strongly Disagree
b) Disagree
c) Neither Agree nor Disagree
d) Agree
e) Strongly Agree

34) I love activities in our English class
a) Strongly Disagree
b) Disagree
c) Neither Agree nor Disagree
d) Agree
e) Strongly Agree

35) Activities in our English class help me to improve English speaking skills
a) Strongly Disagree
b) Disagree
c) Neither Agree nor Disagree
d) Agree
e) Strongly Agree

36) My English teacher does not know how to present things in an interesting manner
a) Strongly Disagree
b) Disagree
c) Neither Agree nor Disagree
d) Agree
e) Strongly Agree 
37) I think that English will help to acquire good job opportunities
a) Strongly Disagree
b) Disagree
c) Neither Agree nor Disagree
d) Agree
e) Strongly Agree

\section{Copyrights}

Copyright for this article is retained by the author, with first publication rights granted to the journal.

This is an open-access article distributed under the terms and conditions of the Creative Commons Attribution license (http://creativecommons.org/licenses/by/4.0/). 